\title{
Prototypic Seizure Activity Driven by Mature Hippocampal Fast-Spiking Interneurons
}

\author{
Yoko Fujiwara-Tsukamoto, ${ }^{1,2}$ Yoshikazu Isomura, ${ }^{1,2,3,4}$ Michiko Imanishi, ${ }^{1}$ Taihei Ninomiya, ${ }^{1,5}$ Minoru Tsukada, ${ }^{2}$ \\ Yuchio Yanagawa, ${ }^{4,6}$ Tomoki Fukai, ${ }^{3}$ and Masahiko Takada ${ }^{1,5}$ \\ ${ }^{1}$ Department of System Neuroscience, Tokyo Metropolitan Institute for Neuroscience, Fuchu, Tokyo 183-8526, Japan, ${ }^{2}$ Brain Science Institute, Tamagawa \\ University, Machida, Tokyo 194-8610, Japan, ${ }^{3}$ Laboratory for Neural Circuit Theory, RIKEN Brain Science Institute, Wako 351-0198, Japan, ${ }^{4}$ JST CREST, \\ Chiyoda-ku, Tokyo 102-0075, Japan, ${ }^{5}$ Systems Neuroscience Section, Primate Research Institute, Kyoto University, Inuyama 484-8506, Japan, and \\ ${ }^{6}$ Department of Genetic and Behavioral Neuroscience, Gunma University Graduate School of Medicine, Maebashi 371-8511, Japan
}

\begin{abstract}
A variety of epileptic seizure models have shown that activation of glutamatergic pyramidal cells is usually required for rhythm generation and/or synchronization in hippocampal seizure-like oscillations in vitro. However, it still remains unclear whether GABAergic interneurons may be able to drive the seizure-like oscillations without glutamatergic transmission. Here, we found that electrical stimulation in rat hippocampal CA1 slices induced a putative prototype of seizure-like oscillations ("prototypic afterdischarge," 1.8 -3.8 Hz) in mature pyramidal cells and interneurons in the presence of ionotropic glutamate receptor antagonists. The prototypic afterdischarge was abolished by $\mathrm{GABA}_{\mathrm{A}}$ receptor antagonists or gap junction blockers, but not by a metabotropic glutamate receptor antagonist or a $\mathrm{GABA}_{\mathrm{B}}$ receptor antagonist. Gramicidin-perforated patch-clamp and voltage-clamp recordings revealed that pyramidal cells were depolarized and frequently excited directly through excitatory GABAergic transmissions in each cycle of the prototypic afterdischarge. Interneurons that were actively spiking during the prototypic afterdischarge were mostly fast-spiking (FS) interneurons located in the strata oriens and pyramidale. Morphologically, these interneurons that might be "potential seizure drivers" included basket, chandelier, and bistratified cells. Furthermore, they received direct excitatory GABAergic input during the prototypic afterdischarge. The 0-LM cells and most of the interneurons in the strata radiatum and lacunosum moleculare were not essential for the generation of prototypic afterdischarge. The GABA-mediated prototypic afterdischarge was observed later than the third postnatal week in the rat hippocampus. Our results suggest that an FS interneuron network alone can drive the prototypic form of electrically induced seizure-like oscillations through their excitatory GABAergic transmissions and presumably through gap junction-mediated communications.
\end{abstract}

\section{Introduction}

To explore the cellular mechanism underlying rhythm generation and synchronization in seizure (ictal) activity of temporal lobe epilepsy (McNamara, 1994), various experimental models using in vitro hippocampal preparations were developed by stimulating neurons electrically (Stasheff et al., 1985), altering the ionic composition of the extracellular environment [low $\mathrm{Ca}^{2+}$ (Jefferys and Haas, 1982; Taylor and Dudek, 1982); low $\mathrm{Mg}^{2+}$ (Anderson et al., 1986); high $\mathrm{K}^{+}$(Traynelis and Dingledine, 1988)], and blocking potassium channels (4-aminopyridine) (Avoli et al., 1993) or $\mathrm{GABA}_{\mathrm{A}}$ receptors (Swann and Brady, 1984; Borck and Jefferys, 1999). Although fast GABAergic transmissions are apparently unnecessary for seizure expression under the low $\mathrm{Ca}^{2+}$ or $\mathrm{GABA}_{\mathrm{A}}$-blocking condition, it is quite possible that hippocampal GABAergic interneurons are involved in the expres-

Received March 25, 2010; revised July 14, 2010; accepted Aug. 17, 2010.

This work was supported by Grants-in-Aids for Scientific Research on Priority Areas (18019042) and for Scientific Research (C) (21500317 and 19500287) from the Ministry of Education, Culture, Sports, Science, and Technology of Japan to Y.F.-T. We thank Dr. A. Miyawaki for providing pCS2-Venus.

Correspondence should be addressed to Yoshikazu Isomura, Brain Science Institute, Tamagawa University, 6-1-1 Tamagawa-gakuen, Machida, Tokyo 194-8610, Japan. E-mail: isomura@lab.tamagawa.ac.jp.

DOI:10.1523/JNEUROSCI.1523-10.2010

Copyright $\odot 2010$ the authors $\quad 0270-6474 / 10 / 3013679-11 \$ 15.00 / 0$ sion of seizure-like activity in other models. In the immature hippocampus, GABA behaves as an excitatory neurotransmitter through $\mathrm{GABA}_{\mathrm{A}}$ receptors (Ben-Ari et al., 1989; Rivera et al., 1999; Ben-Ari, 2002), and GABAergic excitation drives seizurelike activity in similar models (Dzhala and Staley, 2003; Khalilov et al., 2003; Khazipov et al., 2004). Even after postnatal maturation of hippocampal GABAergic synapses, fast GABAergic transmissions can be temporarily converted from inhibitory to depolarizing and excitatory (spike evoking) because of postsynaptic $\mathrm{Cl}^{-}$accumulation in those epileptogenic conditions (Taira et al., 1997; Lamsa and Taira, 2003; Isomura et al., 2003b; Rivera et al., 2004; Kantrowitz et al., 2005; Fujiwara-Tsukamoto et al., 2007) (for review, see Marty and Llano, 2005). This condition often leads to GABA-dependent expression of seizure-like activity (Avoli et al., 1993, 1996; Higashima et al., 1996, 2000; Perez Velazquez and Carlen, 1999; Köhling et al., 2000; FujiwaraTsukamoto et al., 2003, 2006; Isomura et al., 2003a,b; Kaneda et al., 2005). In fact, hippocampal/parahippocampal GABAergic interneurons are preserved in temporal lobe epilepsy patients (Babb et al., 1989) and are capable of depolarizing postsynaptic neurons during spontaneous epileptic activity (Cohen et al., 2002; Huberfeld et al., 2007).

At present, it is still unresolved whether hippocampal interneurons are capable of actively contributing to rhythm genera- 
tion and/or synchronization of seizure-like activity through their excitatory GABAergic transmissions. If seizure-like activity were evoked without glutamatergic excitation, then it might be possible to distinguish a potential "driver" interneuron for the seizure generation from a "follower" (or slave) interneuron recruited by glutamatergic pyramidal cells (Isomura et al., 2008). Yet, most seizure models have failed to preserve seizure-like activity in the presence of glutamate receptor antagonists [electrical stimulation (Perez Velazquez and Carlen, 1999; Fujiwara-Tsukamoto et al., 2003, 2007; Tønnesen et al., 2009); low $\mathrm{Mg}^{2+}$ (Anderson et al., 1986; Fujiwara-Tsukamoto et al., 2006); high $\mathrm{K}^{+}$(Traynelis and Dingledine, 1988); 4-aminopyridine (Avoli et al., 1993, 1996)]. In this study, we found a focal prototypic form of seizurelike activity evocable only near an electrical induction site under a glutamate-blocking condition. This prototypic seizure model has provided direct evidence for excitatory GABAergic synchronization among mature hippocampal neurons during seizurelike activity and has allowed us to identify candidate interneurons for drivers that may participate in rhythm generation of seizurelike activity.

\section{Materials and Methods}

Animals and slice preparations. All experiments were approved by the Animal Care and Use Committee of the Tokyo Metropolitan Institute for Neuroscience and the Tamagawa University Animal Care and Use Committee and, furthermore, were performed in accordance with the Tokyo Metropolitan Institute for Neuroscience Guidelines for Care and Use of Animals. Acute hippocampal slices were prepared from ether- or isoflurane-anesthetized, normal Wistar or vesicular GABA transporter (VGAT)-Venus line A transgenic (Uematsu et al., 2008) rats [male and female at postnatal day 20 (P20) to P31, unless otherwise mentioned]. We cut slices (400 $\mu \mathrm{m}$ thick) with a microslicer (DTK-1500, Dosaka; or VT1200S, Leica Microsystems) and isolated the CA1 region from the CA3 and subiculum. After recovery for at least $1 \mathrm{~h}$, each slice was transferred to a submerged-type recording chamber with continuous circulation of oxygenated $\left(95 \% \mathrm{O}_{2} / 5 \% \mathrm{CO}_{2}\right)$ normal artificial CSF (ACSF; $30-32^{\circ} \mathrm{C}$ ) containing the following (in $\mathrm{mm}$ ): $124 \mathrm{NaCl}, 2.5$ $\mathrm{KCl}, 1.2 \mathrm{KH}_{2} \mathrm{PO}_{4}, 26 \mathrm{NaHCO}_{3}, 1.2 \mathrm{MgSO}_{4}, 2.5 \mathrm{CaCl}_{2}$, and 25 D-glucose (Fujiwara-Tsukamoto et al., 2003).

Electrophysiological recordings. To induce seizure-like activity (seizurelike afterdischarge), intense high-frequency electrical stimulation (HFS; $100 \mathrm{~Hz}$ for $0.5 \mathrm{~s} ; 400 \mu \mathrm{A}$ intensity; $400 \mu$ s duration; 7 to 10 -min intervals) was delivered through a glass stimulating electrode $(0.5-1 \mathrm{M} \Omega$, filled with $2.5 \mathrm{M} \mathrm{NaCl}$ ) placed in the stratum (s.) radiatum (FujiwaraTsukamoto et al., 2003, 2004, 2007). The putative prototypic form of seizure-like afterdischarge (i.e., prototypic afterdischarge) was obtained within a distance of $250 \mu \mathrm{m}$ from the stimulation site in the presence of $10 \mu \mathrm{M}$ 6-cyano-7-nitroquinoxaline-2,3-dione (CNQX; Sigma) and 50 $\mu \mathrm{M}$ DL-2-amino-5-phosphonopentanoic acid (AP-5; Sigma). In the present study, the term "afterdischarge" does not necessarily mean spiking itself, but includes subthreshold (nonspiking) oscillatory responses in association with populational oscillations. These afterdischarge events were observed similarly in 10 and $25 \mathrm{~mm}$ glucose conditions (supplemental Fig. 1, available at www.jneurosci.org as supplemental material). Whole-cell patch-clamp recordings were performed from single pyramidal cells or interneurons in the hippocampal CA1 slices under visual guidance. At an early stage of experiments, some of GABAergic interneurons were identified by using VGAT-Venus transgenic rats that selectively expressed the fluorescent protein Venus under the control of the VGAT promoter. The membrane potentials were recorded using a patchclamp amplifier (Axopatch 1D or Axopatch 200B; Molecular Devices) in the current-clamp mode $(I=0)$ through whole-cell patch electrodes (5-10 M $\Omega$ ) filled with a low- $\mathrm{Cl}^{-}$internal solution containing the following (in mM): $140 \mathrm{~K}$-gluconate, $2 \mathrm{NaCl}, 1 \mathrm{MgCl}_{2}, 10 \mathrm{HEPES}, 0.2 \mathrm{EGTA}, 2$ 5'-ATP $\mathrm{Na}_{2}, 0.5$ GTP $\mathrm{Na}_{2}$, and 10-15 biocytin, $\mathrm{pH} 7.4$ [liquid junction potential $\left(V_{\mathrm{LJ}}\right),+13.7 \mathrm{mV}$ ] (Fujiwara-Tsukamoto et al., 2003, 2004, 2007). The membrane potential was not corrected with liquid junction potential in the present study. In some experiments, we also used a high$\mathrm{Cl}^{-}$internal solution in which $40 \mathrm{mM} \mathrm{KCl}$ was substituted for $40 \mathrm{~mm}$ K-gluconate for reliable detection of oscillatory activity (for pyramidal cells in Figs. 2, 3, and 7). At the end of the recordings, biocytin was loaded sufficiently into the recorded neurons by repetitive current injection $(+300 \mathrm{pA}, 500 \mathrm{~ms}$ at $1 \mathrm{~Hz}$ for $15 \mathrm{~min})$, and the slices were further incubated for 30-60 min in ACSF. The recorded interneurons were characterized electrophysiologically by spiking ability and sag amplitude in response to positive and negative current injections, respectively, as fast-spiking (FS) interneurons (defined as $>100 \mathrm{~Hz} / 0.5 \mathrm{nA}$ spiking and $<20 \%$ sag amplitude) or non-FS interneurons otherwise (see Fig. $4 \mathrm{~A}$ ) (Fujiwara-Tsukamoto et al., 2004, 2007). These interneurons were also characterized by the location of their soma (strata oriens, pyramidale, radiatum, or lacunosum moleculare). In addition, well-visualized interneurons were further identified morphologically. The membrane potential of pyramidal cells and interneurons in the intact $\mathrm{Cl}^{-}$environment was measured by a gramicidin-perforated patch-clamp method, where $0.02-0.1 \mathrm{mg} / \mathrm{ml}$ gramicidin D (Sigma) was dissolved in the low- $\mathrm{Cl}^{-}$ internal solution (5-10 M $\Omega$ ) (Yamada et al., 2004; Fujiwara-Tsukamoto et al., 2006). Voltage-clamp recordings from pyramidal cells were also performed at various holding potentials to measure the reversal potential of the external GABA response using another low- $\mathrm{Cl}^{-}$internal solution containing the following (in $\mathrm{mM}$ ): $132 \mathrm{Cs}$-gluconate, $2 \mathrm{NaCl}, 1 \mathrm{MgCl}_{2}, 10$ HEPES, 2 EGTA, $25^{\prime}$-ATP $\mathrm{Na}_{2}, 0.5$ GTP $\mathrm{Na}_{2}, 10$ biocytin, and 5 QX-314 (lidocaine $N$-ethyl bromide; Alomone Laboratories) $\left(V_{\mathrm{LJ}},+12.8 \mathrm{mV}\right.$; 5-10 M $\Omega$ ) (Fujiwara-Tsukamoto et al., 2007). Series resistance, pipette capacitance, and whole-cell capacitance were compensated appropriately. We did not attempt to conduct voltage-clamp recordings from interneurons because it was technically difficult to keep a prolonged, stable recording against GABA pressure injection and to find a suitable pipette position to apply GABA to morphologically diverse interneurons. When necessary, local field potentials were recorded with the same amplifier(s) through glass electrode(s) $(2-5 \mathrm{M} \Omega$, filled with $2.5 \mathrm{M} \mathrm{NaCl})$ placed in the s. radiatum. Recorded signals were low-pass filtered at 3-5 $\mathrm{kHz}$ and digitized at $10 \mathrm{kHz}$ with an analog-to-digital interface (Digidata 1200, Molecular Devices; or PowerLab 4/25).

Pharmacological reagent applications. Bicuculline methiodide, carbenoxolone, ( \pm )-3-(2-carboxypiperazin-4-yl)propyl-1-phosphonic acid (CРP), kynurenate, 1,2,3,4-tetrahydro-6-nitro-2,3-dioxo-benzo[f]quinoxaline-7sulfonamide disodium salt (NBQX), and octanol were purchased from Sigma; (2S)-3-[[(1S)-1-(3,4-dichlorophenyl)ethyl]amino-2-hydroxypropyl] (phenylmethyl) phosphinic acid (CGP55845) and ( \pm )- $\alpha$-methyl-4carboxyphenylglycine (MCPG) were purchased from Tocris Cookson; other reagents were purchased from Nacalai Tesque. Each reagent was added to the ACSF containing $10 \mu \mathrm{M}$ CNQX and $50 \mu \mathrm{M}$ AP-5 and bath applied to the recorded slices. Only the data obtained from neurons showing more than five cycles of oscillatory responses in the control session were analyzed for quantification in the pharmacological experiments. To monitor the temporal changes in GABA responses, small amounts of $100 \mu \mathrm{M}$ GABA (Sigma) were repeatedly applied by pressure (5-10 psi, 10-150 ms; Picospritzer II, General Valve) to the soma of recorded pyramidal cells through a glass capillary (Fujiwara-Tsukamoto et al., 2007).

Morphological observations. To visualize biocytin-loaded recorded neurons, slices were fixed in $10 \%$ formalin and $15 \%$ saturated picric acid in phosphate buffer, immersed in $0.1 \mathrm{M}$ PBS containing 30\% sucrose, frozen, and cut into $50-\mu \mathrm{m}$-thick sections. The sections were pretreated with $0.3 \% \mathrm{H}_{2} \mathrm{O}_{2}$ in $\mathrm{PBS}$ for 20 min to diminish endogenous peroxidase activity, rinsed in PBS three times, and incubated overnight with avidinbiotin-HRP complex (ABC; 1:100 dilution; Vectastain Elite ABC kit; Vector Laboratories) in PBS containing $0.1 \%$ Triton X-100 at $4^{\circ} \mathrm{C}$. After washing in PBS, the sections were incubated with $0.04 \% \mathrm{NiCl}_{2}$ and $0.04 \%$ diaminobenzidine (Sigma) in $0.05 \mathrm{M}$ Tris- $\mathrm{HCl}$ buffer, $\mathrm{pH}$ 7.6, containing $0.003 \% \mathrm{H}_{2} \mathrm{O}_{2}$ for $5-20 \mathrm{~min}$ at room temperature. The reaction was terminated by washing the sections with PBS. The sections were then embedded on glass slides and coverslipped for camera lucida reconstruction under a light microscope.

Data analysis. All data in the text and figures are reported as the means \pm SD. For statistical comparisons, we used a paired or unpaired (Student's/Welch's) $t$ test, one-way ANOVA with post hoc Duncan's mul- 

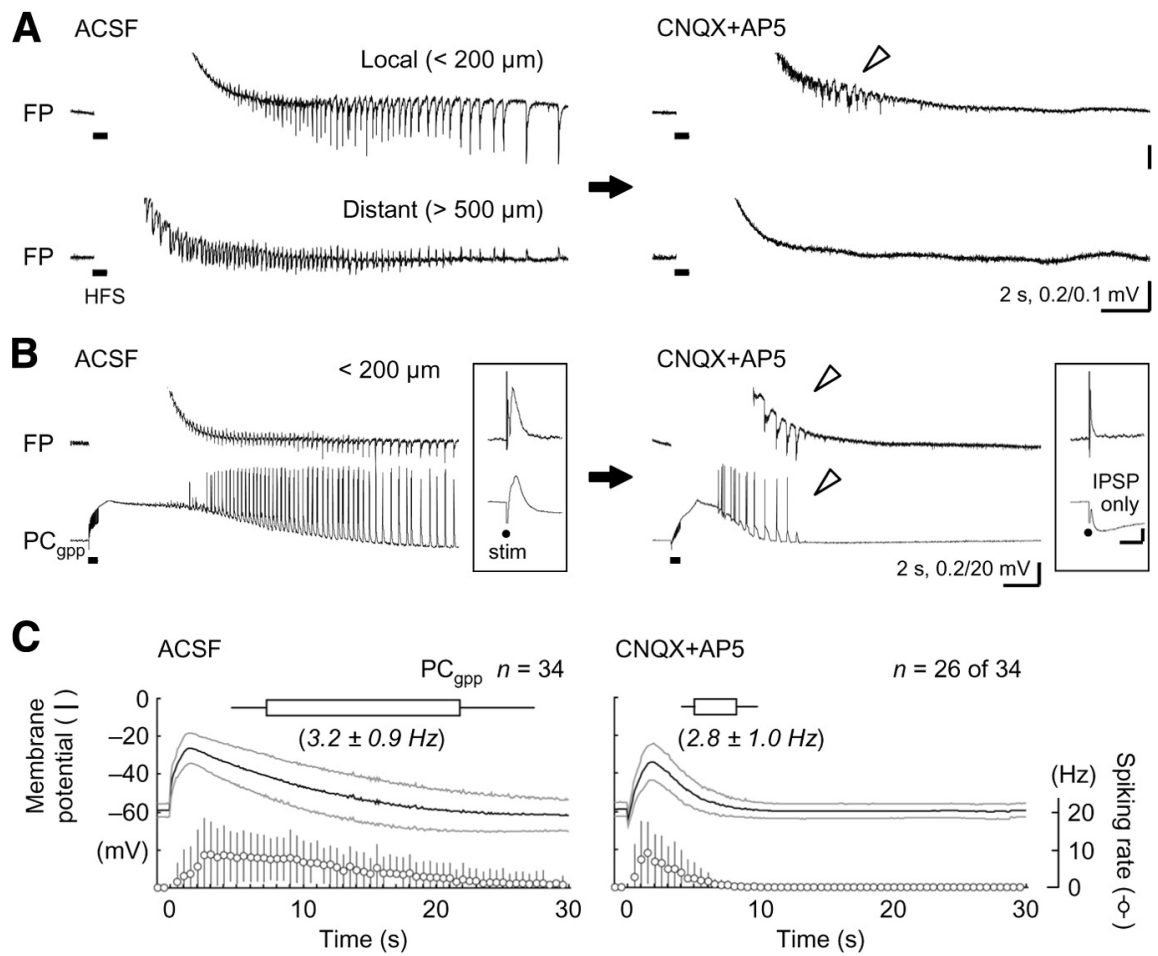

Figure 1. Induction of the prototypic afterdischarge under a glutamate-blocking condition in hippocampal pyramidal cells. $A$, Local field potentials (FP) showing HFS-induced seizure-like afterdischarge in normal ACSF (left) and prototypic afterdischarge in the presence of the ionotropic glutamate receptor antagonists CNQX (10 $\mu \mathrm{M})$ and AP5 (50 $\mu \mathrm{m}$; right). Whereas the seizure-like afterdischarge was observed at both local $(<200 \mu \mathrm{m}$ from the site of stimulation) and distant $(>500 \mu \mathrm{m})$ recording sites, the prototypic afterdischarge (arrowhead) was detected only at the local recording site in the same hippocampal CA1 slice. B, Oscillatory depolarizing responses during the seizure-like afterdischarge (left) and the prototypic afterdischarge (right) in a pyramidal cell recorded in the gramicidin-perforated patch-clamp method $\left(\mathrm{PC}_{\mathrm{gpp}}\right)$. Note that these responses were synchronous with the population spikes in the field potential (top, arrowheads) and that the generation of spikes indicates not only depolarizing but also excitatory responses in the pyramidal cell. Insets, Synaptic responses evoked by a single shock of electrical stimulation (stim). Calibration: $25 \mathrm{~ms}, 0.2$ and $2.5 \mathrm{mV}$. C, Summary of the seizure-like afterdischarge (left) and the prototypic afterdischarge (right) in the pyramidal cells. Top, Time course of the seizure-like and prototypic afterdischarges in the pyramidal cells (boxes and bars indicate the mean and SD of start and end time, respectively). Middle, Membrane potential changes after the electrical induction (spikes were clipped in advance; black and gray lines indicate mean and SD, respectively). Bottom, Spiking rate changes after the electrical induction (circles and bars indicate mean and SD, respectively).

tiple range test, or $\chi^{2}$ test (or Fisher's exact probability test) when appropriate for the data.

\section{Results}

Prototypic afterdischarge: a spatially restricted, short-lasting form of seizure-like afterdischarge

Repetitive electrical stimulation evokes long-lasting, oscillatory, and synchronous discharge activity ("seizure-like afterdischarge"; usually in $1-5 \mathrm{~Hz}$ cycles for 10-60 s) in the hippocampus of mature animals [in vitro, Stasheff et al. (1985, 1989); in vivo, Bragin et al., (1997)] and human epilepsy patients (Gloor et al., 1982). The seizure-like afterdischarge occurs all over the hippocampal areas in synchrony in an all-or-none fashion (Rafiq et al., 1993; Bragin et al., 1997), and the extensive expression of afterdischarge is believed to require both glutamatergic and GABAergic transmissions among pyramidal cells and interneurons (e.g., Fujiwara-Tsukamoto et al., 2003, 2004, 2007; Tønnesen et al., 2009). Consistent with previous observations, local field potential recordings showed that the seizure-like afterdischarge was abolished at a distant location from the stimulation site in the CA1 region in the presence of the AMPA/kainate- and NMDA-type glutamate receptor antagonists CNQX $(10 \mu \mathrm{M})$ and AP-5 $(50 \mu \mathrm{M})$ (Fig. $1 A$, distant) $(n=7$ slices $)$. However, very short-lasting oscillatory activity was observed only near the stimulation site $(<250 \mu \mathrm{m})$ under the same glutamateblocking condition (Fig. $1 A$, local) $(n=6$ of 7 slices). We term this local and brief oscillatory activity "prototypic afterdischarge" in the present study. The time course (start and end timing after the electrical stimulation) of seizure-like afterdischarge was well correlated with that of prototypic afterdischarge in the same slice preparations (supplemental Fig. 2, available at www.jneurosci.org as supplemental material) (start time, $n=165$ slices, $r=0.44, p<0.001$; end time, $r=0.55$, $p<0.001$ ), whereas the frequency of oscillatory responses in seizure-like afterdischarge was quite similar to that in prototypic afterdischarge $(r=-0.037)$. Moreover, both seizure-like and prototypic afterdischarges had a "refractory period" in which one afterdischarge blocked the induction of the next afterdischarge for several minutes (data not shown). These observations suggest that a common rhythm generator may drive these two synchronous oscillations. The membrane potential of the pyramidal cells frequently displayed oscillatory depolarizing responses after a large slow depolarization during the CNQX and AP-5 perfusion in the gramicidin-perforated patch-clamp recording, which should keep their $\mathrm{Cl}^{-}$homeostasis unaffected (Fig. $1 B, C$ ) [duration: ACSF, $14.4 \pm 4.9 \mathrm{~s}(n=34)$; CNQX + AP5, $3.0 \pm 1.3 \mathrm{~s}(n=26$ of 34$) ; t$ test, $p<0.001$; oscillatory cycles: ACSF, $46.4 \pm 20.1$; $\mathrm{CNQX}+\mathrm{AP} 5,7.8 \pm 3.2 ; p<0.001$; frequency: ACSF, $3.2 \pm 0.9 \mathrm{~Hz}$; CNQX+AP5, $2.8 \pm 1.0 \mathrm{~Hz} ; p>0.07]$. Our previous studies showed that the slow depolarization was mediated by GABAergic transmission and extracellular potassium accumulation (Fujiwara-Tsukamoto et al., 2007). During the prototypic afterdischarge, some of the pyramidal cells (10 of 26) synchronously discharged with population spikes in the field potential, which reflected concurrent spike generation by a population of pyramidal cells (Fig. $1 B$ ). The application of CNQX and AP-5 completely blocked excitatory synaptic transmissions through the ionotropic glutamate receptors in the hippocampal CA1 slices (Fig. $1 B$, insets). Therefore, the pyramidal cells appeared to receive excitatory (spike-evoking), nonglutamatergic, synaptic input during the prototypic afterdischarge.

\section{$\mathrm{GABA}_{\mathrm{A}}$-dependent prototypic afterdischarge in pyramidal cells}

By perturbing the intracellular $\mathrm{Cl}^{-}$environment, we determined the synaptic component of the oscillatory depolarizing responses in the pyramidal cells during the prototypic afterdischarge. Although the prototypic afterdischarge occurred in the field potential recording, no obvious oscillatory depolarization was detected in the pyramidal cells recorded through the low $\mathrm{Cl}^{-}$ electrode in the whole-cell current-clamp mode (Fig. $2 \mathrm{~A}$, top) $(n=5)$. In contrast, oscillatory depolarizing responses were very 
clearly observed in most of the pyramidal cells recorded through the high $\mathrm{Cl}^{-}$electrode (Fig. 2A, bottom; supplemental Fig. 3, available at www.jneurosci.org as supplemental material) ( $n=82$ of 98; Fisher's exact probability test, $p<0.001$ for low $\mathrm{Cl}^{-}$vs high $\mathrm{Cl}^{-}$). This suggests that the oscillatory depolarizing responses are dependent on $\mathrm{Cl}^{-}$conductance in the pyramidal cells, probably through $\mathrm{GABA}_{\mathrm{A}}$ receptors. Therefore, we performed voltageclamp recordings at various holding potentials to compare the oscillatory responses with exogenous GABAergic responses during the prototypic afterdischarge in the pyramidal cells. As demonstrated in Figure $2 B$, the reversal potential of oscillatory responses was almost identical to that of the monophasic responses to external GABA puffs during the prototypic afterdischarge $(n=7$; GABA 7 s after HFS, $-73.6 \pm 7.2$ $\mathrm{mV}$; oscillatory activity, $-73.9 \pm 9.5 \mathrm{mV}$; $t$ test, $p>0.9$ ). As expected from the above observations (Fig. $2 \mathrm{~A}$, top), these reversal potentials were kept artificially low, because we used the low- $\mathrm{Cl}^{-}$-based electrode solution in the voltage-clamp mode to avoid possible cell damage from a prolonged, high $\mathrm{Cl}^{-}$recording condition. Electrical stimulation might result in nonspecific loading of $\mathrm{Cl}^{-}$ions into neurons through plasma membrane because of possible damage to them. In fact, extracel-

lularly applied Lucifer yellow, a membrane-impermeable fluorescent dye, did not accumulate inside any neurons in the vicinity of a stimulating electrode during electrical stimulation (supplemental Fig. 4, available at www.jneurosci.org as supplemental material). In addition, the afterdischarge was inducible regardless of the polarity of electrical stimulation (Fujiwara-Tsukamoto et al., 2007). It is, therefore, unlikely that the afterdischarge activity was caused artificially by an electrical trauma to stimulated neurons. These results clearly indicate that the pyramidal cells received excitatory GABAergic synaptic input in each cycle of the prototypic afterdischarge under the glutamateblocking condition.

Moreover, we confirmed the $\mathrm{GABA}_{\mathrm{A}}$-dependent property of the prototypic afterdischarge in a series of pharmacological experiments. The prototypic afterdischarge in the pyramidal cells was detected through the high $\mathrm{Cl}^{-}$electrode for reliable quantification. Additional application of the nonspecific ionotropic glutamate receptor antagonist kynurenate $(2 \mathrm{~mm})$ and the metabotropic glutamate receptor antagonist MCPG (0.5 mM) did not change the expression of the prototypic afterdischarge in the pyramidal cells (Fig. $3 A, E)(n=16$; duration: control, $5.2 \pm$ $4.4 \mathrm{~s}$; kynurenate and MCPG, $4.6 \pm 2.8 \mathrm{~s}$; paired $t$ test, $p>0.5$; oscillatory cycles: control, $10.4 \pm 5.8$; kynurenate and MCPG, $9.1 \pm 7.2 ; p>0.1)$. The prototypic afterdischarge was expressed in the presence of a higher concentration $(20-40 \mu \mathrm{M})$ of CNQX and $50 \mu \mathrm{M} \mathrm{AP}-5$, as well as other glutamate receptor antagonists (e.g., 10-20 $\mu \mathrm{M}$ NBQX and $10 \mu \mathrm{M}$ CPP) (data not shown). Thus, the prototypic afterdischarge was evoked by electrical stimulation without any glutamatergic transmission. In contrast, the $\mathrm{GABA}_{\mathrm{A}}$ receptor antagonist bicuculline $(25 \mu \mathrm{M})$ abolished the prototypic afterdischarge (Fig. $3 B, E)(n=14$; duration: control, $4.0 \pm 1.2 \mathrm{~s}$; bicuculline, $0 \pm 0 \mathrm{~s} ; p<0.001$; oscillatory cycles: control, $9.9 \pm$ 3.9; bicuculline, $0 \pm 0$; $p<0.001$ ). The size of slow depolarization was also reduced as previously reported (Fujiwara-Tsukamoto et al., 2007). On the other hand, the $\mathrm{GABA}_{\mathrm{B}}$ receptor antagonist CGP55845 $(1 \mu \mathrm{M})$ did not affect the expression of the prototypic afterdischarge (Fig. 3C,E) $(n=13$; duration: control, $5.6 \pm 3.5 \mathrm{~s}$; CGP55845, $5.4 \pm 2.8 \mathrm{~s} ; p>0.8$; oscillatory cycles: control, $11.4 \pm$ 5.1; CGP55845, $9.5 \pm 5.5 ; p>0.1$ ). The prototypic afterdischarge was almost completely diminished by the nonspecific gap junction blocker carbenoxolone (100 $\mu \mathrm{M})$ (Fig. $3 D, E)(n=13$; duration: control, $4.0 \pm 1.9 \mathrm{~s}$; carbenoxolone, $0.1 \pm 0.3 \mathrm{~s} ; p<0.001$; oscillatory cycles: control, $9.8 \pm 4.6$; carbenoxolone, $0.2 \pm 0.6$; $p<0.001)$. Similar results were obtained by the application of another gap junction blocker octanol (1 mM) (data not shown). Unlike the low-Ca ${ }^{2+}$-induced seizure model (Konnerth et al., 1986), the prototypic afterdischarge in the field potential disappeared after a reduction in extracellular $\mathrm{Ca}^{2+}$ concentration (nominally $0 \mathrm{~mm}$ ) (supplemental Fig. 5, available at www.jneurosci.org as supplemental material). Together, it is likely that the prototypic afterdischarge was driven by synaptic excitation through $\mathrm{GABA}_{\mathrm{A}}$ receptors and possible electrical communication via gap junctions, but not by glutamatergic excitation, in a local network of the hippocampus.

\section{Interneuron subtypes participating in prototypic afterdischarge}

Because the spiking pyramidal cells would no longer activate interneurons as well as other pyramidal cells during the prototypic afterdischarge under the glutamate-blocking condition, they can be regarded as "followers" for the generation of the prototypic 

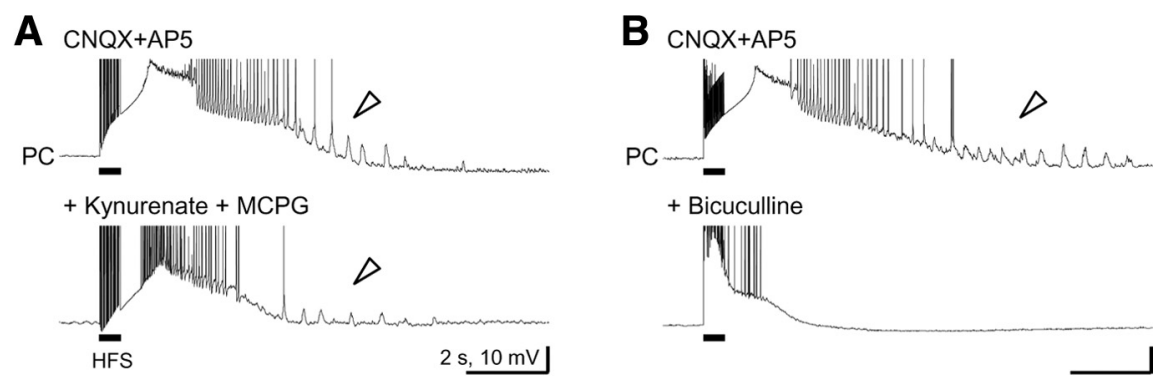

C

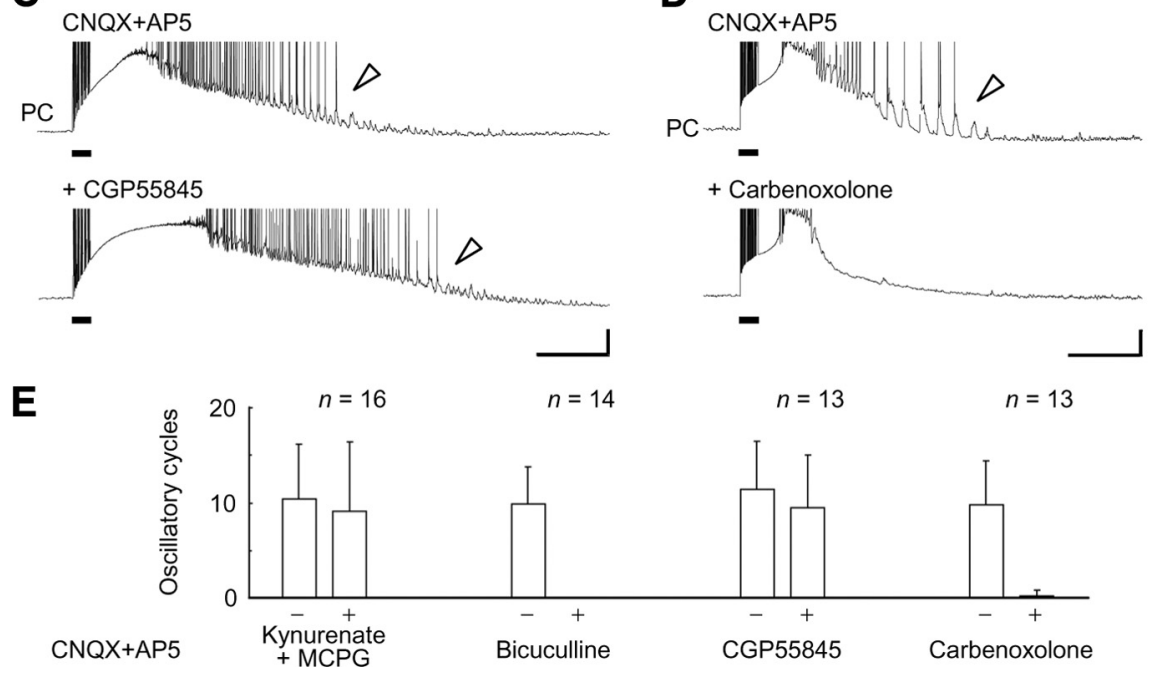

Figure 3. Pharmacological characterization of the prototypic afterdischarge in pyramidal cells. $A$, No effect of additional application of the nonspecific ionotropic glutamate receptor antagonist kynurenate $(2 \mathrm{mM})$ and the metabotropic glutamate receptor antagonist MCPG $(0.5 \mathrm{~mm})$ on the expression of the prototypic afterdischarge in pyramidal cells (arrowheads). Action potentials are truncated for display. $\boldsymbol{B}$, Complete abolishment of the expression of the prototypic afterdischarge by additional application of the $G_{A B A}$ receptor antagonist bicuculline $(25 \mu \mathrm{M})$. C, No effect of the $G A B A_{B}$ receptor antagonist CGP55845 $(1 \mu \mathrm{M})$ on the prototypic afterdischarge expression (arrowheads). D, Abolishment of the prototypic afterdischarge expression by the gap junction blocker carbenoxolone $(100 \mu \mathrm{m})$. $\boldsymbol{E}$, Summary of the effects of these antagonists or the blocker on the expression of the prototypic afterdischarge in pyramidal cells. All of the pyramidal cells were recorded through the high $\mathrm{Cl}^{-}$electrodes for reliable detection of the prototypic afterdischarge (see Fig. 2).

afterdischarge. Given that the pyramidal cells receive excitatory GABAergic input during the prototypic afterdischarge, some presynaptic GABAergic interneurons must discharge at the same time as the oscillatory depolarizing responses in the postsynaptic pyramidal cells. To identify the candidates for such "driver" interneurons, we surveyed the spiking ability of a variety of interneurons in relation to the populational prototypic afterdischarge monitored in the field potential (Fig. $4 A)(n=151$ in total; 41 FS and 91 non-FS interneurons in the strata oriens and pyramidale, 19 non-FS interneurons in the strata radiatum and lacunosum moleculare). The spike width at one-half amplitude was significantly smaller in the FS interneuron group $(0.59 \pm 0.25 \mathrm{~ms})$ compared to the non-FS interneuron group $(1.03 \pm 0.39 \mathrm{~ms} ; t$ test, $p<0.001$ ). In the strata oriens and pyramidale, $61 \%$ of the FS interneurons displayed spiking oscillatory responses during the prototypic afterdischarge, which was more than twice as high as the percentage of non-FS interneurons with spiking oscillatory responses $\left(29 \% ; \chi^{2}\right.$ test, $\left.p<0.001\right)$. On average, the spiking activity in the prototypic afterdischarge cycles was $1.03 \pm 1.50$ spikes/cycle in the FS interneuron group and $0.31 \pm 0.67$ spikes/ cycle in the non-FS interneuron group $(t$ test, $p<0.001)$. The time course and frequency of prototypic afterdischarge activity in the oscillatory spiking FS/non-FS interneurons $(n=51)$ were very similar to those in the pyramidal cells, whereas the slow depolarization followed by the prototypic afterdischarge in the interneurons was smaller than that in the pyramidal cells (compare Figs. $1 C$, right, $4 B$ ). The oscillatory responses of these interneurons were always synchronous with the prototypic afterdischarge in the field potential. The FS interneurons increased spike activity earlier in the oscillatory cycles than the pyramidal cells (supplemental Figure 6, available at www.jneurosci.org as supplemental material) [start of spike increase, pyramidal cells, $+4 \mathrm{~ms}$ (from the onset of field potential responses); interneurons, $-13 \mathrm{~ms}$; latency at one-half amplitude, pyramidal cells, $+6 \mathrm{~ms}$; interneurons, -7 ms; peak latency, pyramidal cells, $+9 \mathrm{~ms}$; interneurons, $+5 \mathrm{~ms}]$. Unlike those FS/ non-FS interneurons, most of the non-FS interneurons in the strata radiatum and lacunosum moleculare (84\%) did not show any oscillatory responses during the prototypic afterdischarge (Fig. $4 A$ ).

Hippocampal interneurons occasionally possess an intrinsically bursting property (Fig. $4 C$, top left, top graph) or a spike-pausing property (Fig. $4 C$, top left, bottom graph) in response to depolarizing current injection, both of which could bring about the rhythm of the prototypic afterdischarge. However, the bursting property was displayed only by the interneurons with no oscillatory responses during the prototypic afterdischarge, and the pausing property was observed regardless of the difference in oscillatory responses (Fig. 4C, bottom). The occurrence of spikelets, which might arise from ectopic spiking in distal dendrites or in a different neuron via gap junctions, was observed very rarely in the present study (supplemental Fig. 7, available at www.jneurosci.org as supplemental material) $(n=2)$. Thus, these properties were not directly correlated with the occurrence of spiking oscillations during the prototypic afterdischarge. Interestingly, we often found a distinct spiking oscillatory activity that transiently appeared in the membrane potential of interneurons before the onset of the prototypic afterdischarge in the field potential ("preoscillatory bursting") (Fig. 4C, top right). Preoscillatory bursting was observed predominantly in FS interneurons showing spiking oscillations of subsequent prototypic afterdischarge (Fig. $4 C$, bottom, $D)\left(\chi^{2}\right.$ test, $p<0.001$ ), suggesting that preoscillatory bursting may be involved in the initiation or acceleration of the prototypic afterdischarge.

Furthermore, 118 of the 151 interneurons recorded were visualized and classified morphologically into basket/chandelier cells, bistratified cells, O-LM cells, and others (Freund and Buzsáki, 1996; Somogyi and Klausberger, 2005). We found no clear dye coupling in the interneurons visualized here (data not shown). The major population of hippocampal FS interneurons was composed of basket, chandelier, and bistratified cells, whereas none of the FS interneurons were O-LM cells (supplemental Fig. 8, available at www.jneurosci.org as supplemental material). As expected, more than half of the basket/chandelier 

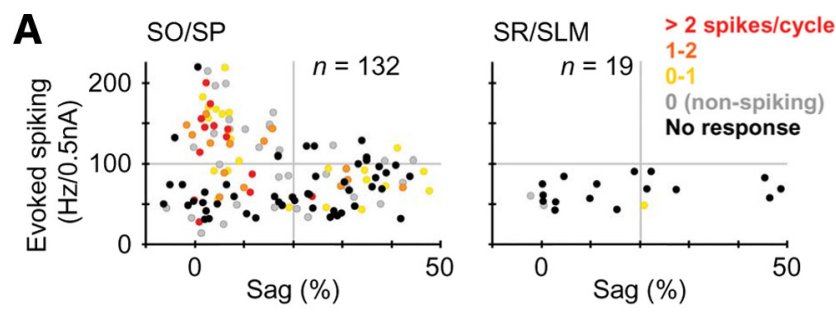

B

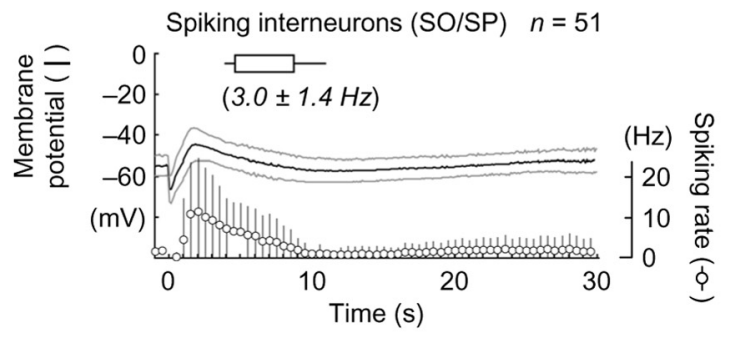

C
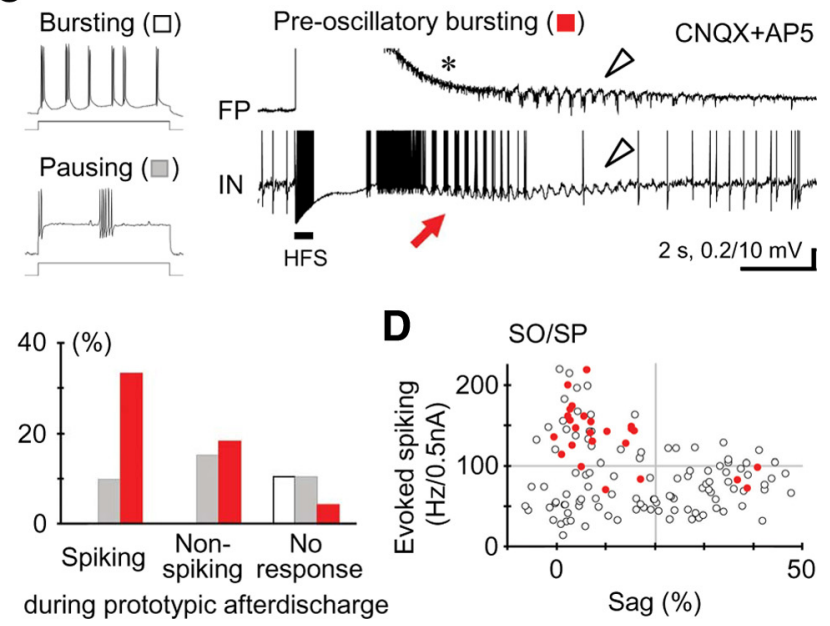

Figure 4. Electrophysiological properties of hippocampal interneurons showing the prototypic afterdischarge. $\boldsymbol{A}$, Spiking activity in the prototypic afterdischarge cycles in individual interneurons with different electrophysiological properties (spiking ability and sag amplitude) in the strata oriens and pyramidale (left) and the strata radiatum and lacunosum moleculare (right). Each dot represents a single interneuron, and the color indicates the spiking ability [spikes/cycle; 0 (nonspiking), oscillatory responses with no spiking; No response, no oscillatory responses]. We defined an FS interneuron as $>100 \mathrm{~Hz} / 0.5 \mathrm{nA}$ spiking and $<20 \%$ sag amplitude (left, top left quadrant) (see Materials and Methods). $\boldsymbol{B}$, Time course of the prototypic afterdischarge (top), membrane potential changes (middle), and spiking rate changes (bottom) in the interneurons with spiking oscillatory responses (compare Fig. 1C). C, Top, Representative traces illustrating an intrinsically bursting property (left, top) and a spike-pausing property (left, bottom) in response to depolarizing current injection and a preoscillatory bursting (right). Note that the preoscillatory bursting (red arrow) appeared in the interneuron, but not in the field potential (asterisk), earlier than the prototypic afterdischarge (arrowheads). Bottom, Population ratios of interneurons showing the bursting property (open), pausing property (gray), and preoscillatory bursting (red) in the interneurons with spiking and nonspiking oscillatory responses and with no oscillatory responses. $\boldsymbol{D}$, Electrophysiological properties of interneurons showing the preoscillatory bursting activity (red) in the strata oriens and pyramidale ( $\boldsymbol{A}$, left). Most of these interneurons were categorized as FS interneurons.

cells $(n=15$ of 27$)$ and the bistratified cells $(n=6$ of 11$)$ displayed spiking oscillatory responses in the prototypic afterdischarge cycles (Fig. 5A, $B, E$ ). Some other basket/chandelier cells $(n=5)$ and bistratified cells $(n=4)$ also showed subthreshold oscillatory responses during the prototypic afterdischarge. In contrast, most of the O-LM cells ( $n=17$ of 26) displayed no spiking oscillatory responses (Fig. $5 \mathrm{C}$ ), and as a whole, the spiking activity of O-LM cells was substantially weak during the prototypic afterdischarge compared with the basket/chandelier cells
(Fig. 5E; supplemental Fig. 8, available at www.jneurosci.org as supplemental material) (ANOVA, $p<0.001$; basket/chandelier, $0.99 \pm 1.68$ spikes/cycle; O-LM, $0.31 \pm 0.68$ spikes/cycle; Duncan's multiple range test, $p<0.05)$. Almost none of the interneurons located in the strata radiatum and lacunosum moleculare were correlated with the prototypic afterdischarge activity (Fig. $5 D, E)$. As O-LM cells in the s. oriens, which display a pacemaker activity via $I_{\mathrm{h}}$ current (Maccaferri and McBain, 1996), send axons toward the s. lacunosum moleculare and synapse onto distal apical dendrites of the pyramidal cells, the spiking O-LM cells may be required for the expression of the prototypic afterdischarge in the pyramidal cells via their apical dendrites. However, we excluded this possibility because the prototypic afterdischarge in the pyramidal cells or in the field potential was preserved in the SLM-cut slices in which the s. lacunosum moleculare was cut off mechanically (Fig. $5 F)(n=7$ slices).

$\mathrm{GABA}_{\mathrm{A}}$-dependent prototypic afterdischarge in interneurons As shown above, the pyramidal cells received synchronous excitatory inputs directly from GABAergic interneurons in the strata oriens and pyramidale during the prototypic afterdischarge. Then, a major question arises how the s. oriens and s. pyramidale interneurons are synchronized with each other during the prototypic afterdischarge. In our pharmacological experiments, the application of bicuculline completely abolished the prototypic afterdischarge in all but one of the interneurons examined (Fig. $6 \mathrm{~A}, C)(n=29$; duration: control, $4.2 \pm 2.5 \mathrm{~s}$; bicuculline, $0.2 \pm$ $1.0 \mathrm{~s} ; p<0.001$; oscillatory cycles: control, $11.8 \pm 4.7$; bicuculline, $0.3 \pm 1.7 ; p<0.001)$. Similarly, the application of carbenoxolone abolished the prototypic afterdischarge in all of the interneurons (Fig. $6 B, C)(n=9$; duration: control, $4.2 \pm 1.0 \mathrm{~s}$; carbenoxolone, $0 \pm 0 \mathrm{~s} ; p<0.001$; oscillatory cycles: control, $12.1 \pm 3.0$; carbenoxolone, $0 \pm 0 ; p<0.001)$. Thus, the interneurons in the strata oriens and pyramidale displayed the prototypic afterdischarge in a $\mathrm{GABA}_{\mathrm{A}}$-dependent and presumably gap junction-dependent manner. The sole interneuron showing bicuculline-resistant oscillatory activity could play a distinct role in rhythm generation of the prototypic afterdischarge.

Next, we examined the polarity of spontaneous and evoked postsynaptic potentials in the interneurons before, during, and after the prototypic afterdischarge $(n=10)$. In a representative basket cell (Fig. 6D), the waveform of spontaneous postsynaptic potentials was hyperpolarizing in the resting state, whereas the hyperpolarizing postsynaptic potentials seemed to disappear after the induction of the prototypic afterdischarge. In addition, a single shock of electrical stimulation, which usually evoked a large, hyperpolarizing, $\mathrm{GABA}_{\mathrm{A}}$-dependent postsynaptic potential under the glutamate-blocking condition, transiently evoked depolarizing responses similar to one cycle of its oscillatory responses during the prototypic afterdischarge. Importantly, the electrical stimulation also caused remarkable spiking activity after the induction of the prototypic afterdischarge, indicating that the evoked responses were excitatory. We observed such evoked depolarizing/excitatory responses in six (two depolarizing and four excitatory) of the 10 interneurons tested in the strata oriens and pyramidale; five of these six neurons displayed spiking oscillatory responses during the prototypic afterdischarge (supplemental Fig. $9 A-D$, available at www.jneurosci.org as supplemental material). In our gramicidin-perforated patch-clamp recordings, interneurons in the strata oriens and pyramidale exhibited excitatory (spike-evoking) responses in each cycle of the prototypic afterdischarge (Fig. 6E) and excitatory/depolarizing responses to external GABA application after the electrical stim- 

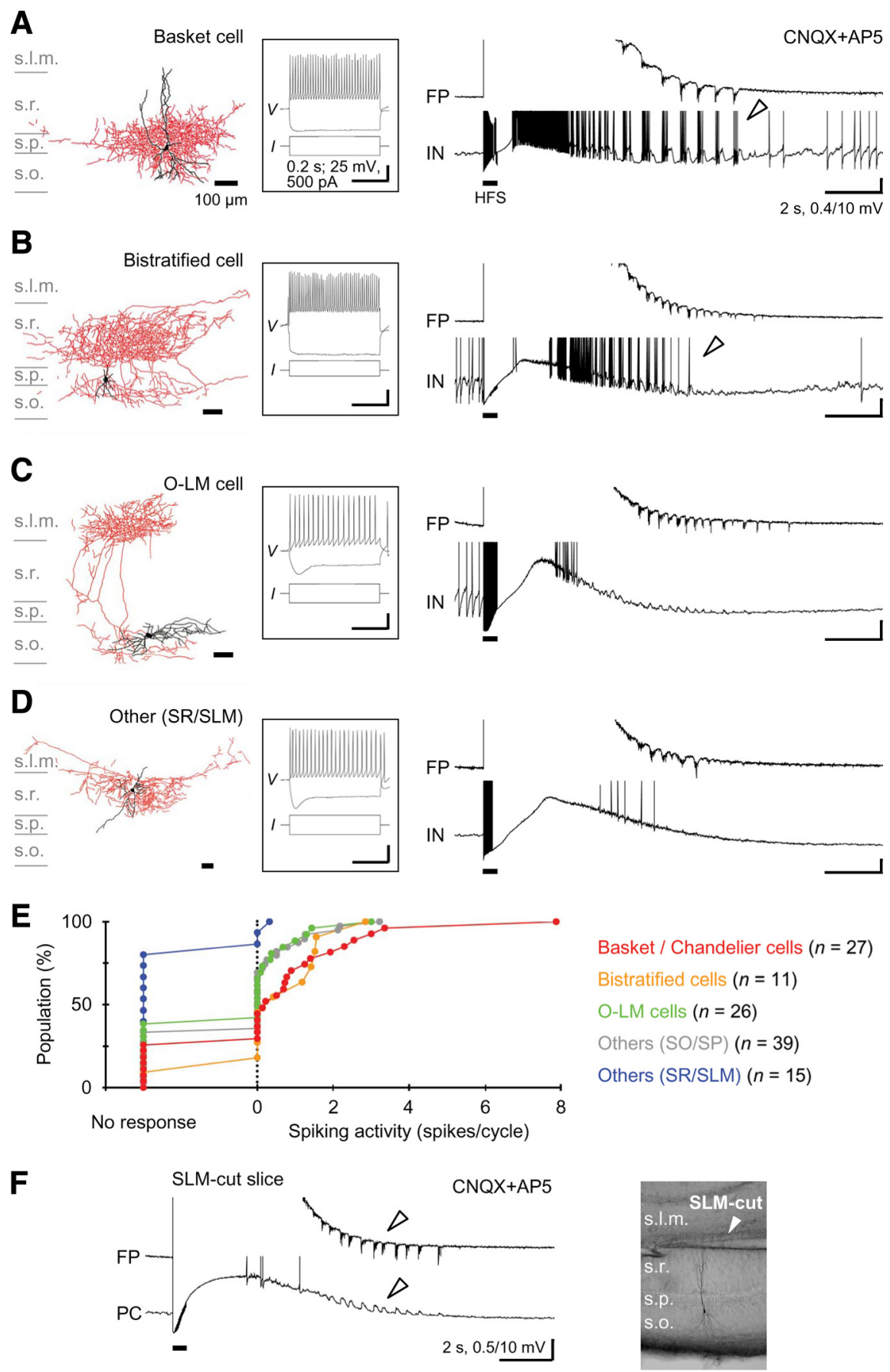

Figure 5. Morphological identification of interneurons showing the prototypic afterdischarge. $A$, A basket cell showing oscillatory depolarizing responses with robust spiking (arrowhead) during the prototypic afterdischarge in the field potential. Left, Morphology of the recorded and visualized neuron (black, soma and dendrites; red, axons). Middle, Membrane potential responses to depolarizing and hyperpolarizing current injections. Right, Field potential and membrane potential traces during the prototypic afterdischarge. Calibrations are the same in $\boldsymbol{A}-\boldsymbol{D} \cdot \boldsymbol{B}$, A bistratified cell showing oscillatory depolarizing responses with spiking during the prototypic afterdischarge (arrowhead). These two interneurons were categorized as FS interneurons. C, An 0-LM cell showing oscillatory depolarizing responses without spiking during the prototypic afterdischarge. $\boldsymbol{D}$, Another type of interneuron located in the s. radiatum close to the $s$. lacunosum moleculare showing no oscillatory responses during the prototypic afterdischarge. $\boldsymbol{E}$, Cumulative distribution of spiking activity in the prototypic afterdischarge cycles (zero means nonspiking oscillatory responses) in different groups of morphologically visualized interneurons. $F$, Preservation of the prototypic afterdischarge generation (left, arrowheads) without the s. lacunosum moleculare (right). s.l.m., s. lacunosum moleculare; s.r., s. radiatum; s.p., s. pyramidale; s.o., s. oriens.

ulation (Fig. $6 F)(n=6)$. Thus, it is likely that synchronization among the strata oriens and pyramidale interneurons may be accomplished by transient $\mathrm{GABA}_{\mathrm{A}}$-mediated excitation and gap junction-mediated communication.

\section{Lack of prototypic afterdischarge in} immature hippocampus

In neonatal hippocampal neurons, normal GABAergic transmissions have resulted in depolarizing and excitatory responses because of a positive shift in the $\mathrm{GABA}_{\mathrm{A}}$ reversal potential (Ben-Ari et al., 1989; Rivera et al., 1999; Ben-Ari, 2002). This suggests that the prototypic afterdischarge might be induced more readily in an immature hippocampal network. However, we could not detect clearly the oscillatory activity of prototypic afterdischarge in either the pyramidal cells or the field potentials before the third postnatal week, and it became continually inducible in juvenile and young adult rats (Fig. $7 A, B)(\mathrm{P} 6-\mathrm{P} 7,0 \pm 0$ oscillatory cycles, $n=8$; P12-P14, $0.6 \pm 1.0, n=12$; P19-P21, 7.6 $\pm 3.0, n=5$; P26-P28, $8.0 \pm$ 7.2, $n=27$; P44-P57, $10.8 \pm 6.6, n=5$; one-way ANOVA, $p<0.001$; Duncan's multiple range test, $p<0.05$ for $\mathrm{P} 6-\mathrm{P} 7 /$ P12-P14 vs P19-21; $p<0.01$ for P6-P7/ P12-P14 vs P26-P28/P44-P57). The developmental profile of the prototypic afterdischarge ran parallel with that of the seizure-like afterdischarge (FujiwaraTsukamoto et al., 2003), both of which require temporary synaptic excitation through $\mathrm{GABA}_{\mathrm{A}}$ receptors.

\section{Discussion}

In the present study, we have established a local and brief seizure-precursor model, "prototypic afterdischarge," that was induced by electrical stimulation in the absence of glutamatergic transmission in the mature rat hippocampus in vitro. Our observations revealed that both glutamatergic pyramidal cells and GABAergic interneurons were activated in synchrony during the prototypic afterdischarge in the vicinity of the stimulation site. The pyramidal cells directly received depolarizing GABAergic input in each cycle of the prototypic afterdischarge, and often reached the spike threshold to generate action potentials, indicating direct synaptic excitation mediated through $\mathrm{GABA}_{\mathrm{A}}$ receptors (Figs. 1-3). The pyramidal cells themselves, however, could never activate other pyramidal cells or interneurons, at least synaptically, in the presence of glutamate receptor antagonists even if they discharged well. The pyramidal cells have virtually no gap junctions with interneurons in the hippocampus. Therefore, all of the pyramidal cells should be regarded as followers for the prototypic afterdischarge (Fig. $8 A$ ), because they cannot contribute to its synchronization or rhythm generation among hippocampal neurons. Similarly, interneurons that did not discharge during the prototypic afterdischarge should be regarded as followers. 


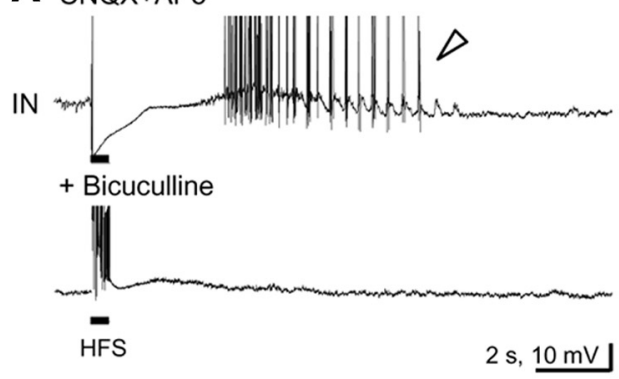

A $C N Q X+A P 5$

B
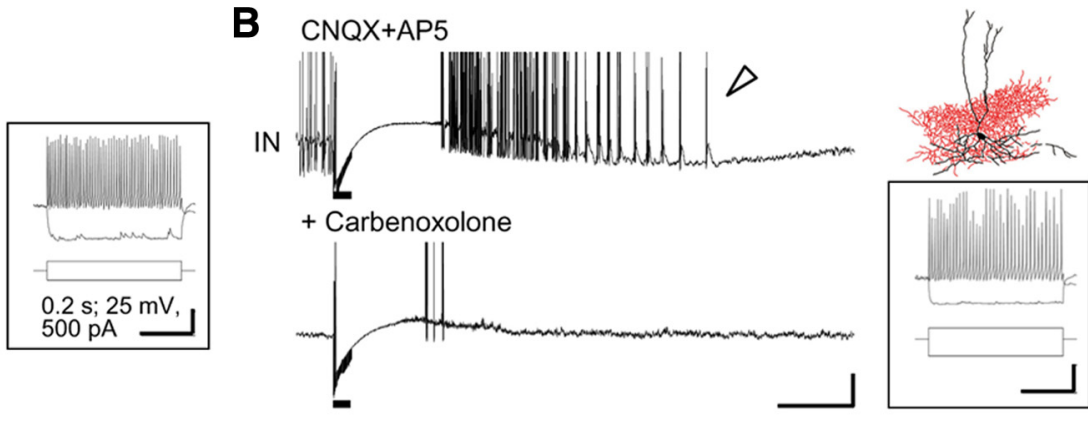

C

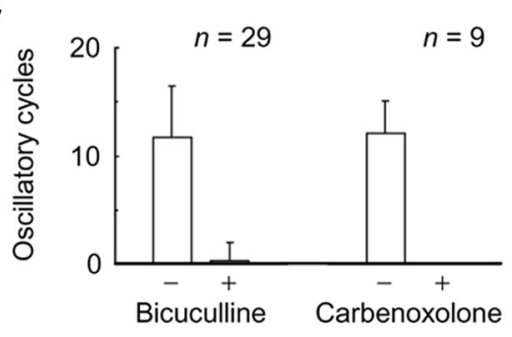

CNQX+AP5
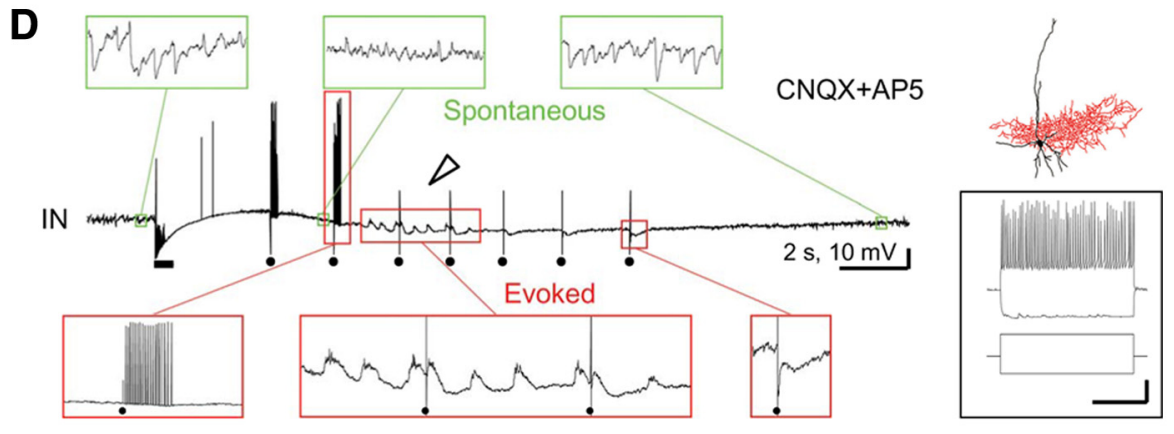

CNQX+AP5

E CNQX+AP5

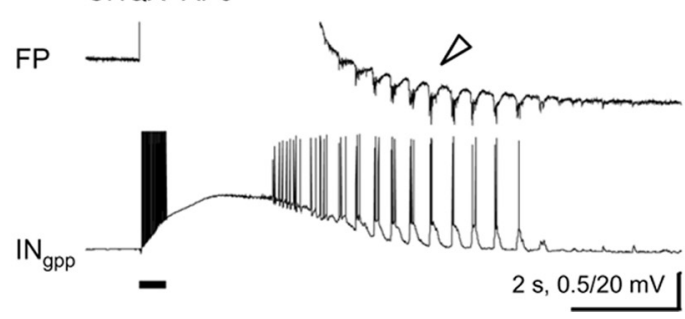

$\mathbf{F}$

Figure 6. The prototypic afterdischarge mediated through $\mathrm{GABA}_{A}$ receptors and gap junctions among interneurons. $A$, Abolishment of the prototypic afterdischarge in an $\mathrm{FS}$ interneuron by the application of $25 \mu \mathrm{m}$ bicuculline. Calibrations are the same in $\boldsymbol{A}, \boldsymbol{B}$, and $\boldsymbol{D}$. $\boldsymbol{B}$, Abolishment of the prototypic afterdischarge in a basket cell by $100 \mu \mathrm{m}$ carbenoxolone. $\boldsymbol{C}$, Summary of the effects of bicuculline and carbenoxolone on the prototypic afterdischarge in interneurons. $\boldsymbol{D}$, Spontaneous (green boxes) and evoked (red boxes) postsynaptic potentials around the prototypic afterdischarge expression (arrowhead) in another basket cell. Note that spontaneous hyperpolarizing postsynaptic potentials appeared only in the resting state (top, left and right) and that single shocks of electrical stimulation (dots) evoked excitatory (bottom left), depolarizing (bottom middle), and hyperpolarizing (bottom right) responses. E, Excitatory (spike-evoking) oscillatory responses during the prototypic afterdischarge in an interneuron recorded with the gramicidin-perforated patch-clamp method ( $\left(\mathrm{N}_{\mathrm{gpp}}\right)$. $\boldsymbol{F}$, Excitatory/depolarizing responses to external GABA application (triangles) after HFS in the gramicidin-perforated patch-clamp condition.

Consequently, we defined the driver candidates as the interneurons that showed spiking activity required for synaptic excitation of other neurons during the prototypic afterdischarge (Fig. $8 \mathrm{~A}$ ).

From an electrophysiological viewpoint, the driver candidates for the prototypic afterdischarge were mostly FS interneurons located in the strata oriens and pyramidale (Fig. 4). Morphologically, these interneurons included basket cells, chandelier cells, and bistratified cells (Fig. 5; supplemental Fig. 8, available at www.jneurosci.org as supplemental material), which synapsed onto the somata, axonal initial segments, and apical and basal dendrites of pyramidal cells, respectively (Freund and Buzsáki, 1996; Maccaferri et al., 2000; Somogyi and Klausberger, 2005). Thus, these interneurons can function as potential drivers to activate the pyramidal cells directly through excitatory GABAergic transmissions during the prototypic afterdischarge. The predominant contribution of FS interneurons to the prototypic afterdischarge expression was quite consistent with the activity profile of interneurons during the seizure-like afterdischarge (FujiwaraTsukamoto et al., 2004). The O-LM cells, belonging typically to the non-FS interneuron group, also sometimes discharged in cycles of the prototypic afterdischarge; however, they were not necessary for driving the oscillatory activity, which ordinarily occurred without major synaptic input from the O-LM cells (Fig. $5 F)$. Almost all of the non-FS interneurons located in the strata radiatum and lacunosum moleculare were too silent to affect the oscillatory activity in a hippocampal network. Nevertheless, we cannot rule out the possibility that part of other non-FS interneurons in the strata oriens and pyramidale may also participate, more or less, in the synchronization and rhythm generation of the prototypic afterdischarge.

Under a glutamate-blocking condition, an excitatory $\mathrm{GABA}_{\mathrm{A}}$ action was observed transiently after electrical stimulation in mature hippocampal interneurons in the strata oriens and pyramidale (Lamsa and Taira, 2003). Our results also suggest that GABA often exerts a role as depolarizing and excitatory signals to interneurons as well as to the pyramidal cells close to the stimulation site during the prototypic afterdischarge (Fig. 6). In our previous study, electrical stimulation at a distant $(>250 \mu \mathrm{m})$ site caused a greater elevation in the reversal potential of GABAergic responses in the pyramidal cells than in interneurons (not classified) during the seizure-like afterdischarge, but the large elevation of reversal potentials in distant pyramidal cells was diminished by glutamate receptor antagonism (Fujiwara-Tsukamoto et al., 2007). In addition to synaptic excitation, neighboring FS interneurons are 

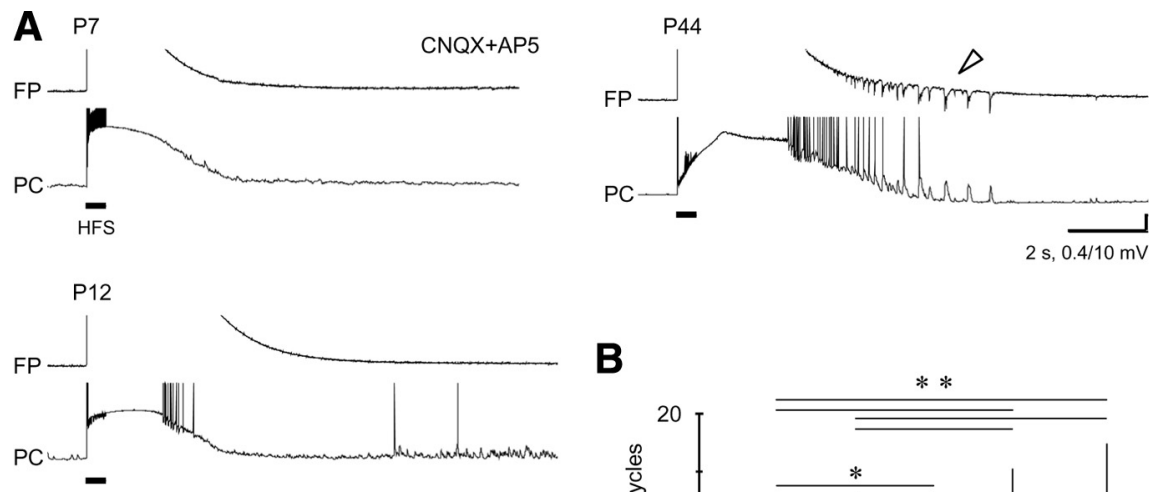

B

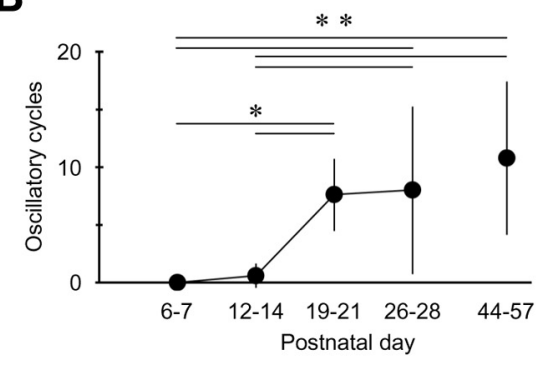

(1st) $\quad(2 \mathrm{nd}) \quad(3 \mathrm{rd}) \quad(4$ th) $\quad(>6$ week $)$

Figure 7. Lack of the prototypic afterdischarge in an early developmental stage. $A$, Representative trials of electrical induction of the prototypic afterdischarge on postnatal days $7,12,19$, and 44 . Note that the prototypic afterdischarge appeared in field potential and pyramidal cells after the third postnatal week (P19 and P44; arrowheads). $\boldsymbol{B}$, Postnatal development of the prototypic afterdischarge in pyramidal cells. ${ }^{*} p<0.05 ;{ }^{* *} p<0.01$. All of the pyramidal cells were recorded through the high- $\mathrm{Cl}^{-}$ electrodes for reliable detection of the prototypic afterdischarge (see Fig. 2).
A Prototypic afterdischarge

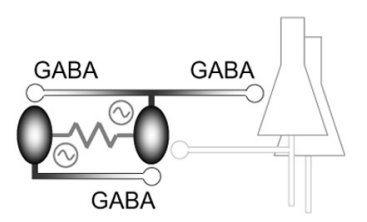

Interneurons Pyramidal cells "drivers"
B Seizure-like afterdischarge

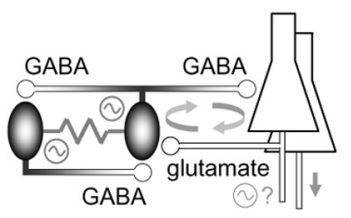

Interneurons Pyramidal cells "drivers" "enhancers" ?
Figure 8. Schematic diagrams on network mechanisms underlying prototypic afterdischarge and seizure-like afterdischarge. $\boldsymbol{A}$, Rhythm generation among FS interneurons through excitatory GABAergic transmissions and gap junctions during prototypic afterdischarge. $\boldsymbol{B}, \mathbf{E n}$ hancement of afterdischarge activity by glutamatergic pyramidal cells during seizure-like afterdischarge. See Discussion for details.

mutually connected via gap junctions electrically (Fukuda and Kosaka, 2000). Therefore, it is quite possible that the driver FS interneurons activate one another locally via excitatory GABAergic transmissions and presumably via gap junctions, thereby achieving the spatially limited neuronal synchronization in the prototypic afterdischarge. Furthermore, the same FS interneuron network may be able to generate the rhythm itself for the prototypic afterdischarge. The correlation in time course between the seizure-like afterdischarge (with glutamate) and the prototypic afterdischarge (without glutamate), both of which have an identical oscillation frequency, supports the idea that a common rhythm generator exists within the FS interneuron network (see supplemental Fig. 2, available at www.jneurosci.org as supplemental material). According to our previous estimation, the sufficient network size for rhythm generation would include a hundred interneurons in the strata oriens and pyramidale (Fujiwara-Tsukamoto et al., 2007). Interestingly, the preoscillatory bursting was frequently observed in spiking FS interneurons, but not in the pyramidal cells (see Fig. $4 C, D$ ). It could serve as an initiator/accelerator for more rhythmic and synchronous net- work activity of the prototypic afterdischarge. It is known that similar electrical stimulation induces a brief synchronous discharge activity at gamma/beta frequency $(>10 \mathrm{~Hz})$, which precedes the seizure-like afterdischarge in a glutamateindependent and GABA-dependent manner (Bracci et al., 1999; Id Bihi et al., 2005). This electrically induced gamma/ beta activity may be relevant to the preoscillatory bursting that we have observed in the present study.

In many other seizure models, glutamatergic pyramidal cells, but not GABAergic interneurons, are considered the central driver for seizure generation in a mature hippocampal network. Apparently, the generation of low-Ca ${ }^{2+}$ - or $\mathrm{GABA}_{\mathrm{A}}$-blockade-induced seizures never requires GABA-dependent synaptic transmissions among hippocampal neurons (Jefferys and Haas, 1982; Taylor and Dudek, 1982; Swann and Brady, 1984; Borck and Jefferys, 1999). The generation of 4-aminopyridine-induced seizures depends on glutamatergic synaptic excitations by the pyramidal cells (Avoli et al., 1993, 1996). The action of GABAergic input remains inhibitory during the seizures (Lopantsev and Avoli, 1998), and the pyramidal cells alternately discharge with interneurons in the $\mathrm{s}$. oriens (Ziburkus et al., 2006). The generation of low- $\mathrm{Mg}^{2+}$-induced seizures is also dependent on the activation of glutamate receptors, in particular, the NMDA-type receptors (Anderson et al., 1986; Traub et al., 1994; Fujiwara-Tsukamoto et al., 2006). Intriguingly, GABAergic transmissions may become depolarizing in the pyramidal cells and interneurons in low- $\mathrm{Mg}^{2+}$-induced epileptic conditions (Köhling et al., 2000; Perez Velazquez, 2003; Rivera et al., 2004; Fujiwara-Tsukamoto et al., 2006), and interneurons are coincidently activated with the pyramidal cells during the seizures (FujiwaraTsukamoto et al., 2006; Lasztóczi et al., 2009). Hence, the pyramidal cells should be the major drivers for the low- $\mathrm{Mg}^{2+}$-induced seizures, whereas the interneurons might promote seizure generation through excitatory GABAergic transmissions (Köhling et al., 2000). In contrast with the so-far-appreciated seizure models, we suggest that the FS interneurons, but not the pyramidal cells, may be the primary driver neurons for the electrically induced prototypic afterdischarge. The major follower, i.e., the pyramidal cells, may accomplish the full-scale seizure-like afterdischarge by spatially spreading synchronization among remote neurons as well as by temporally elongating the oscillatory activity, probably because of their glutamatergic excitation and secondary extracellular $\mathrm{K}^{+}$increase (Fujiwara-Tsukamoto et al., 2007). The seizure-like activity further propagates to different hippocampal areas through axonal projections from the pyramidal cells (Isomura et al., 2003a). In this context, the pyramidal cells can be considered the "enhancer" as well as the follower for the electrically induced afterdischarge (Fig. $8 B$ ). The interneuron-driver mechanism, which seems paradoxical in the mature hippocampus (see Fig. 7), may underlie not only the electrically induced afterdischarge, but also at least one of the spontaneous (nonelectrically occurring) seizures in vitro (i.e., $\mathrm{GABA}_{\mathrm{B}}$-antagonism-induced seizure) (Uusisaari et al., 2002).

In the present study, we demonstrated that some subtypes of GABAergic interneurons have their own ability to achieve rhythm generation and synchronization in the seizure-like after- 
discharge once their inhibitory effects turn excitatory. The GABAergic interneurons have been shown to be preserved in the hippocampus of epilepsy patients (Babb et al., 1989) and, indeed, to display depolarizing/excitatory synaptic transmissions during epileptic activity (Cohen et al., 2002; Huberfeld et al., 2007). Thus, it is possible that the driver group of either the pyramidal cells or the interneurons may alternatively elicit seizure generation in individual epilepsy patients. Unfortunately, it would be clinically challenging to identify the cell type of seizure-driving neurons, the pyramidal cells or interneurons, inside a small primary focus of the epileptic temporal lobe. The different cell types of driver neurons may reflect the diversity of epileptogenesis, which could account for the reported ineffectiveness of systemic administration of antiepileptic drugs that potentiate $\mathrm{GABA}_{\mathrm{A}}$ actions, e.g., barbiturates and benzodiazepines, in some intractable cases of temporal lobe epilepsy. In summary, our findings of the seizure-driving ability of mature hippocampal interneurons via excitatory GABA actions may shed light on the heterogeneity of rhythm generation and synchronization of seizure activity among human epilepsy patients, as well as among various seizure models in vitro and in vivo.

\section{References}

Anderson WW, Lewis DV, Swartzwelder HS, Wilson WA (1986) Magnesiumfree medium activates seizure-like events in the rat hippocampal slice. Brain Res 398:215-219.

Avoli M, Psarropoulou C, Tancredi V, Fueta Y (1993) On the synchronous activity induced by 4 -aminopyridine in the CA3 subfield of juvenile rat hippocampus. J Neurophysiol 70:1018-1029.

Avoli M, Barbarosie M, Lücke A, Nagao T, Lopantsev V, Köhling R (1996) Synchronous GABA-mediated potentials and epileptiform discharges in the rat limbic system in vitro. J Neurosci 16:3912-3924.

Babb TL, Pretorius JK, Kupfer WR, Crandall PH (1989) Glutamate decarboxylase-immunoreactive neurons are preserved in human epileptic hippocampus. J Neurosci 9:2562-2574.

Ben-Ari Y (2002) Excitatory actions of GABA during development: the nature of the nurture. Nat Rev Neurosci 3:728-739.

Ben-Ari Y, Cherubini E, Corradetti R, Gaiarsa JL (1989) Giant synaptic potentials in immature rat CA3 hippocampal neurones. J Physiol 416:303-325.

Borck C, Jefferys JG (1999) Seizure-like events in disinhibited ventral slices of adult rat hippocampus. J Neurophysiol 82:2130-2142.

Bracci E, Vreugdenhil M, Hack SP, Jefferys JGR (1999) On the synchronizing mechanisms of tetanically induced hippocampal oscillations. J Neurosci 19:8104-8113.

Bragin A, Csicsvári J, Penttonen M, Buzsáki G (1997) Epileptic afterdischarge in the hippocampal-entorhinal system: current source density and unit studies. Neuroscience 76:1187-1203.

Cohen I, Navarro V, Clemenceau S, Baulac M, Miles R (2002) On the origin of interictal activity in human temporal lobe epilepsy in vitro. Science 298:1418-1421.

Dzhala VI, Staley KJ (2003) Excitatory actions of endogenously released GABA contribute to initiation of ictal epileptiform activity in the developing hippocampus. J Neurosci 23:1840-1846.

Freund TF, Buzsáki G (1996) Interneurons of the hippocampus. Hippocampus 6:347-470.

Fujiwara-Tsukamoto Y, Isomura Y, Nambu A, Takada M (2003) Excitatory GABA input directly drives seizure-like rhythmic synchronization in mature hippocampal CA1 pyramidal cells. Neuroscience 119:265-275.

Fujiwara-Tsukamoto Y, Isomura Y, Kaneda K, Takada M (2004) Synaptic interactions between pyramidal cells and interneurone subtypes during seizure-like activity in the rat hippocampus. J Physiol 557:961-979.

Fujiwara-Tsukamoto Y, Isomura Y, Takada M (2006) Comparable GABAergic mechanisms of hippocampal seizurelike activity in posttetanic and low$\mathrm{Mg}^{2+}$ conditions. J Neurophysiol 95:2013-2019.

Fujiwara-Tsukamoto Y, Isomura Y, Imanishi M, Fukai T, Takada M (2007) Distinct types of ionic modulation of GABA actions in pyramidal cells and interneurons during electrical induction of hippocampal seizure-like network activity. Eur J Neurosci 25:2713-2725.
Fukuda T, Kosaka T (2000) Gap junctions linking the dendritic network of GABAergic interneurons in the hippocampus. J Neurosci 20:1519-1528.

Gloor P, Olivier A, Quesney LF, Andermann F, Horowitz S (1982) The role of the limbic system in experiential phenomena of temporal lobe epilepsy. Ann Neurol 12:129-144.

Higashima M, Kinoshita H, Yamaguchi N, Koshino Y (1996) Activation of GABAergic function necessary for afterdischarge generation in rat hippocampal slices. Neurosci Lett 207:101-104.

Higashima M, Ohno K, Kinoshita H, Koshino Y (2000) Involvement of $\mathrm{GABA}_{\mathrm{A}}$ and $\mathrm{GABA}_{\mathrm{B}}$ receptors in afterdischarge generation in rat hippocampal slices. Brain Res 865:186-193.

Huberfeld G, Wittner L, Clemenceau S, Baulac M, Kaila K, Miles R, Rivera C (2007) Perturbed chloride homeostasis and GABAergic signaling in human temporal lobe epilepsy. J Neurosci 27:9866-9873.

Id Bihi R, Jefferys JGR, Vreugdenhil M (2005) The role of extracellular potassium in the epileptogenic transformation of recurrent GABAergic inhibition. Epilepsia 46[Suppl 5]:64-71.

Isomura Y, Fujiwara-Tsukamoto Y, Takada M (2003a) Glutamatergic propagation of GABAergic seizure-like afterdischarge in the hippocampus in vitro. J Neurophysiol 90:2746-2751.

Isomura Y, Sugimoto M, Fujiwara-Tsukamoto Y, Yamamoto-Muraki S, Yamada J, Fukuda A (2003b) Synaptically activated $\mathrm{Cl}^{-}$accumulation responsible for depolarizing GABAergic responses in mature hippocampal neurons. J Neurophysiol 90:2752-2756.

Isomura Y, Fujiwara-Tsukamoto Y, Takada M (2008) A network mechanism underlying hippocampal seizure-like synchronous oscillations. Neurosci Res 61:227-233.

Jefferys JG, Haas HL (1982) Synchronized bursting of CA1 hippocampal pyramidal cells in the absence of synaptic transmission. Nature 300:448-450.

Kaneda K, Fujiwara-Tsukamoto Y, Isomura Y, Takada M (2005) Regionspecific modulation of electrically induced synchronous oscillations in the rat hippocampus and cerebral cortex. Neurosci Res 52:83-94.

Kantrowitz JT, Francis NN, Salah A, Perkins KL (2005) Synaptic depolarizing GABA response in adults is excitatory and proconvulsive when $\mathrm{GABA}_{\mathrm{B}}$ receptors are blocked. J Neurophysiol 93:2656-2667.

Khalilov I, Holmes GL, Ben-Ari Y (2003) In vitro formation of a secondary epileptogenic mirror focus by interhippocampal propagation of seizures. Nat Neurosci 6:1079-1085.

Khazipov R, Khalilov I, Tyzio R, Morozova E, Ben-Ari Y, Holmes GL (2004) Developmental changes in GABAergic actions and seizure susceptibility in the rat hippocampus. Eur J Neurosci 19:590-600.

Köhling R, Vreugdenhil M, Bracci E, Jefferys JG (2000) Ictal epileptiform activity is facilitated by hippocampal $\mathrm{GABA}_{\mathrm{A}}$ receptor-mediated oscillations. J Neurosci 20:6820-6829.

Konnerth A, Heinemann U, Yaari Y (1986) Nonsynaptic epileptogenesis in the mammalian hippocampus in vitro. I. Development of seizurelike activity in low extracellular calcium. J Neurophysiol 56:409-423.

Lamsa K, Taira T (2003) Use-dependent shift from inhibitory to excitatory $\mathrm{GABA}_{\mathrm{A}}$ receptor action in SP-O interneurons in the rat hippocampal CA3 area. J Neurophysiol 90:1983-1995.

Lasztóczi B, Nyitrai G, Héja L, Kardos J (2009) Synchronization of GABAergic inputs to CA3 pyramidal cells precedes seizure-like event onset in juvenile rat hippocampal slices. J Neurophysiol 102:2538-2553.

Lopantsev V, Avoli M (1998) Participation of $\mathrm{GABA}_{\mathrm{A}}$-mediated inhibition in ictallike discharges in the rat entorhinal cortex. J Neurophysiol 79:352-360.

Maccaferri G, McBain CJ (1996) The hyperpolarization-activated current $\left(I_{\mathrm{h}}\right)$ and its contribution to pacemaker activity in rat CA1 hippocampal stratum oriens-alveus interneurones. J Physiol 497:119-130.

Maccaferri G, Roberts JD, Szucs P, Cottingham CA, Somogyi P (2000) Cell surface domain specific postsynaptic currents evoked by identified GABAergic neurones in rat hippocampus in vitro. J Physiol 524:91-116.

Marty A, Llano I (2005) Excitatory effects of GABA in established brain networks. Trends Neurosci 28:284-289.

McNamara JO (1994) Cellular and molecular basis of epilepsy. J Neurosci 14:3413-3425.

Perez Velazquez JL (2003) Bicarbonate-dependent depolarizing potentials in pyramidal cells and interneurons during epileptiform activity. Eur J Neurosci 18:1337-1342.

Perez Velazquez JL, Carlen PL (1999) Synchronization of GABAergic inter- 
neuronal networks during seizure-like activity in the rat horizontal hippocampal slice. Eur J Neurosci 11:4110-4118.

Rafiq A, DeLorenzo RJ, Coulter DA (1993) Generation and propagation of epileptiform discharges in a combined entorhinal cortex/hippocampal slice. J Neurophysiol 70:1962-1974.

Rivera C, Voipio J, Payne JA, Ruusuvuori E, Lahtinen H, Lamsa K, Pirvola U, Saarma M, Kaila K (1999) The $\mathrm{K}^{+} / \mathrm{Cl}^{-}$co-transporter KCC2 renders GABA hyperpolarizing during neuronal maturation. Nature 397:251255.

Rivera C, Voipio J, Thomas-Crusells J, Li H, Emri Z, Sipilä S, Payne JA, Minichiello L, Saarma M, Kaila K (2004) Mechanism of activity-dependent downregulation of the neuron-specific K-Cl cotransporter KCC2. J Neurosci 24:4683-4691.

Somogyi P, Klausberger T (2005) Defined types of cortical interneurone structure space and spike timing in the hippocampus. J Physiol 562:9-26.

Stasheff SF, Bragdon AC, Wilson WA (1985) Induction of epileptiform activity in hippocampal slices by trains of electrical stimuli. Brain Res 344:296-302.

Stasheff SF, Anderson WW, Clark S, Wilson WA (1989) NMDA antagonists differentiate epileptogenesis from seizure expression in an in vitro model. Science 245:648-651.

Swann JW, Brady RJ (1984) Penicillin-induced epileptogenesis in immature rat CA3 hippocampal pyramidal cells. Dev Brain Res 12:243-254.

Taira T, Lamsa K, Kaila K (1997) Posttetanic excitation mediated by GABA receptors in rat CA1 pyramidal neurons. J Neurophysiol 77:2213-2218.
Taylor CP, Dudek FE (1982) Synchronous neural afterdischarges in rat hippocampal slices without active chemical synapses. Science 218:810-812.

Tønnesen J, Sørensen AT, Deisseroth K, Lundberg C, Kokaia M (2009) Optogenetic control of epileptiform activity. Proc Natl Acad Sci U S A 106:12162-12167.

Traub RD, Jefferys JG, Whittington MA (1994) Enhanced NMDA conductance can account for epileptiform activity induced by low $\mathrm{Mg}^{2+}$ in the rat hippocampal slice. J Physiol 478:379-393.

Traynelis SF, Dingledine R (1988) Potassium-induced spontaneous electrographic seizures in the rat hippocampal slice. J Neurophysiol 59:259-276.

Uematsu M, Hirai Y, Karube F, Ebihara S, Kato M, Abe K, Obata K, Yoshida S, Hirabayashi M, Yanagawa Y, Kawaguchi Y (2008) Quantitative chemical composition of cortical GABAergic neurons revealed in transgenic Venus-expressing rats. Cereb Cortex 18:315-330.

Uusisaari M, Smirnov S, Voipio J, Kaila K (2002) Spontaneous epileptiform activity mediated by $\mathrm{GABA}_{\mathrm{A}}$ receptors and gap junctions in the rat hippocampal slice after long-term exposure to $\mathrm{GABA}_{B}$ antagonists. Neuropharmacology 43:563-572.

Yamada J, Okabe A, Toyoda H, Kilb W, Luhmann HJ, Fukuda A (2004) $\mathrm{Cl}^{-}$ uptake promoting depolarizing GABA actions in immature rat neocortical neurones is mediated by NKCC1. J Physiol 557:829-841.

Ziburkus J, Cressman JR, Barreto E, Schiff SJ (2006) Interneuron and pyramidal cell interplay during in vitro seizure-like events. J Neurophysiol 95:3948-3954. 